\section{Scheduling of Resource-Constrained Projects}

\section{R Klein}

Kluwer Academic Publishers, 1999. xvi 369 pp. £103.50. ISBN 0-7923-8637-X

I was surprised to find that a book with over 300 pages could be written about the resource-constrained project scheduling problem (RCPSP) but the author of this book has done all this and more. I had not realised how extensive is the research field related to RCPSP.

The book starts with two chapters that provide a good general introduction to concepts such as CPM, crashing, activity-on-node, activity-on-arrow (here called arc) and resource constraints. The chapters are all about breaking the scheduling problem into components ready for analysis. These chapters are good, if a little clinical, but the manuscript of the book would have benefited from another read through by a native English speaker to get rid of annoying lapses of style. In these introductory chapters there are only a few pages where commercially available software is described. This is deliberate, says the author, because the field changes rapidly. Clearly this part of the book is not embedded in software models, giving rise to certain disadvantages in the presentation of material whilst offering the advantage of independence.

In Chapter 3 the author develops the more specialised area of modelling RCPSPs. Various modifications of the basic models are considered. At this stage of the book the reader will begin to ponder whether most of the chapters in the book were developed for a doctoral thesis. The layout of the book is structured rather like a thesis, but helpful detail seems to have been added which was unlikely to come from the same source.

After the modelling is complete in Chapter 3, (lower) bounds are computed in Chapter 4 for the length of the project. Some bounds are quite simple, arising from considering a relaxation of the problem, while others arise from known problems, for example bin packing. Many approaches (over 20) are developed for various models. No computational results are presented here, but are to be found in Chapter 7. While reading Chapters 4-6 it is tempting to refer to Chapter 7 and flick backwards and forwards. The author has chosen to get all description out of the way and leave the results to the last. I suspect the book would have been easier to read if individual chapters contained a section on results, but that is my personal preference.

In Chapter 5 there is a very comprehensive review of heuristics for RCPSP. As mentioned before, I did not realise so many existed. Then in Chapter 6 exact procedures are described. The author has some very interesting points to make about branch and bound. The most exciting development, for me at least, is the notion of trying to get the benefit of tabu search within branch and bound. The author calls this 'scattered branch and bound.'
Then, at last, we reach the computational results chapter. Results derived from using the author's algorithms are compared, successfully, with results from the work of others. The author's ideas are also compared to methods embedded within Microsoft Project and Computer Associates' SuperProject. This chapter is easily the most interesting part of the book, but it has been a slow, albeit rewarding, journey to get there.

The final chapter is very disappointing. It contains just 7 pages and is a re-run of the contents pages with some more detail. No food for thought is offered, except in the final paragraph. This ending seems particularly disappointing when you have worked through over 300 pages to get there. Even a thesis usually has more conclusions.

This is a book to dip into. The content is excellent and will be of assistance to researchers in the field. Some additional material, as indicated would have been welcome and some changes in structure helpful, but once you know where to look in the book you will not be disappointed.

Loughborough University

J Wilson

\section{Synergy Matters; Working with Systems in the 21st Century}

AM Castell, AJ Gregory, GA Hindle, ME James and G Ragsdell (Eds)

Kluwer Academic/Plenum Publishers, 1999, xviii + 657 pp. $£ 113.75$.

ISBN 0306461862

I think this is a book that one can judge pretty well by its cover; or at least by its cover, contents pages and index. The book is the proceedings of Sixth International Conference of the United Kingdom Systems Society (UKSS), held 5-9 July, 1999. With 109 papers, and the trans-disciplinary nature of the systems movement, there is almost bound to be something for everyone. On the other hand, specialists in a particular discipline are likely to find that only a few of the papers seem relevant to them.

The contents pages helpfully group the papers into sections, and there is also a useful index. Analysis of these suggests that of specialists, those with an interest in Information Systems (IS) or Soft Systems Methodology (SSM) may be most likely to find papers of interest to them. It also confirms that, despite the name, System Dynamics is not a major interest for 'systems' people.

The sections where I found the highest density of useful information, however, were those on critical systems thinking, community and social systems research and organisational learning; the least useful sections being business and management, IS and student papers. This must cast some doubt on the relevance of the book to IS specialists, although the benefits I gained from each section seemed to be in proportion to my previous knowledge and interest in 